\title{
I Congreso de la Profesión Médica de Cataluña: la formación de los médicos
}

\author{
Josep Carreras. Departament de Ciències Fisiológiques I. Facultat de Medicina. Universitat de Barcelona
}

Los días 19 y 20 del pasado mes de noviembre, organizado por el Consejo de Colegios de Médicos de Cataluña, tuvo lugar en la localidad de Sitges el I Congreso de la Profesión Médica de Cataluña. Según palabras del Dr. Miquel Bruguera, presidente del Comité Organizador, la celebración del congreso significaba "abrir un proceso que ha de permitir el debate permanente sobre los problemas que afectan la profesión, y la búsqueda de soluciones". Su finalidad era "revisar cual ha de ser, a principios del Siglo XXI, el papel del médico en una sociedad que ha experimentado cambios tan considerables en el terreno social, económico y de valores, y que previsiblemente experimentará más en el futuro inmediato. (....) El congreso ha de permitir el debate sobre los problemas que nos afectan y ha de concluir con posicionamientos bien definidos y claros sobre la profesión médica, la enseñanza de la medicina y la organización profesional". Y entre sus objetivos específicos se hallaba "revisar los procedimientos formativos de los estudiantes de medicina y de los médicos en formación para el mantenimiento de la competencia".

La temática del congreso se estructuró en cinco ponencias (cada una de las cuales se dividió en tres subponencias), encargadas a 150 expertos "reconocidos, solventes y plurales": "Ser médico en el Siglo XXI", "Educación de los médicos y mantenimiento de la competencia", "Aspectos jurídico-legales del ejercicio de la medicina", "Las condiciones de trabajo de los médicos" e "Instrumentos para la cohesión profesional". El texto de cada subponencia contendría un "diagnóstico" o descripción del estado de la cuestión, un "pronóstico" o previsión de futuro, y un "tratamiento" o propuestas de mejora. Además, para cada subponencia se elaborarían diez preguntas concretas sobre las cuales debería pronunciarse el congreso a "fin de conocer el grado de compromiso de los médicos con cada una de las propuestas de cambio". Por otra parte, se preparó una sesión dedicada a la "Actualización del Código Deontológico Médico".

Para asegurar el carácter "abierto, participativo y representativo" del congreso, se eligieron, mediante sorteo informático, 1036 delegados (uno para cada treinta de los más de 31.000 colegiados de los cuatro Colegios de Médicos de Cataluña) que, sumados a los delegados natos constituidos por los autores de las ponencias, los redactores de la propuesta de actualización del código deontológico y representantes de las Juntas de Gobierno de los Colegios y de diversas instituciones y entidades médicas de Cataluña, formarían el total de unos 1200 congresistas con voz y voto. Los colegiales no elegidos como delegados que desearan asistir al congreso podrían hacerlo como asistentes invitados, seleccionados hasta completar el aforo por orden de inscripción.

La convocatoria del congreso se hizo en marzo del año 2003. El mes de mayo del año 2004 tuvo lugar la elección de los delegados y la publicación en la web oficial del congreso de los textos preliminares de las ponencias, a las cuales los delegados pudieron hacer aportaciones hasta mitad de junio. Los textos definitivos se dieron a conocer el mes de octubre; pudiendo los delegados solicitar, mediante la presentación del correspondiente resumen, su intervención oral en el plenario del congreso para defender sus opiniones. Ya en el congreso, en cada sesión, el presidente de la ponencia correspondiente, después de exponer un resumen de la misma, fue presentando el texto de cada subponencia. Tomaron la palabra los delegados que lo habían solicitado (hasta cinco durante dos minutos cada uno) y, después de votar el texto de la subponencia, se votaron las diez preguntas correspondientes, mediante el sistema de respuesta múltiple. Las votaciones, individuales y secretas, se realizaron 
electrónicamente; de manera que los resultados se fueron conociendo de forma inmediata. Los mismos deberán servir de base para la elaboración de las conclusiones por parte de la Mesa del Congreso, que serán ampliamente difundidas. Los textos definitivos que fueron sometidos a votación y los resultados de las votaciones pueden consultarse a través de la web del congreso (www.congresprofessio.org). Los textos preliminares se hallan en la publicación "Congrésprofessió. Full n ${ }^{\circ}$ 1, octubre de 2004" del "Consell de Col.legis de Metges de Catalunya".

Las tres subponencias de la Ponencia $2^{\mathrm{a}}$, "Educación de los médicos y mantenimiento de la competencia", fueron: "Formar médicos. ¿Para qué y cuantos?. Contenidos de la enseñanza de la medicina; “¿Es necesario reformar el MIR?”, y "Formación continuada, evaluación periódica de la competencia".

En la Subponencia $1^{\mathrm{a}}$, después de analizar la situación actual y las previsiones futuras, se señala como primera propuesta la urgente definición de los objetivos de la formación de grado y de postgrado, en términos de competencias y habilidades que deben alcanzarse; con la aplicación de los recursos económicos, técnicos y de profesorado necesarios. Respecto al profesorado, se indica que, a fin de incentivar su entrega, motivación y responsabilidad, son necesarias tanto una retribución adecuada como la evaluación periódica de la actividad docente. Los recursos técnicos deben hallarse en sintonía con la metodología docente más moderna, y toda la estructura sanitaria debe utilizarse, previa acreditación, para la docencia. Deben establecerse criterios para ajustar el número de estudiantes admitidos a las necesidades reales, de acuerdo con la política sanitaria y teniendo en cuenta las consecuencias de la feminización de la profesión. Finalmente, la subponencia recomienda que se evalúe la formación especializada de postgrado al final del período de formación, tanto para asegurar la adquisición del nivel adecuado como para evaluar indirectamente los centros responsables de la misma.

Se manifestaron de acuerdo con la subponencia un $94 \%$ de los más de 400 delegados presentes. Por lo que hace a su posicionamiento respecto a las diez preguntas formuladas, cabe destacar que un $46 \%$ valoraron como muy mejorable la calidad de la enseñanza actualmente impartida en las Facultades de Medicina, y que un $95 \%$ consideraron que debían definirse unos contenidos comunes para todas las Facultades, si bien un $43 \%$ opinaron que los mismos debían ser mínimos y básicos. Un $69 \%$ de los delegados consideró que en los órganos de gobierno de las Facultades deberían haber representantes de la sociedad civil y de la profesión, y un $62 \%$ opinó que la determinación del número de estudiantes de nuevo ingreso debería hacerla un organismo externo responsable de estudios sobre demografía médica.

La Subponencia $2^{\text {a }}$, aprobada por un $95 \%$ de los delegados, señala como primera propuesta de mejora la necesidad de que la prueba de acceso al MIR evalúe adecuadamente, no sólo los conocimientos teóricos, sino también las competencias clínicas, prácticas y de comunicación; competencias que deben determinarse por amplio consenso social. Indica la conveniencia de un sistema MIR troncal y permeable; la necesidad de replantearse el equilibrio entre las actividades docentes y asistenciales, de profesionalizar y formar en habilidades docentes los tutores, de desarrollar sistemas de evaluación continuada, de fortalecer las Comisiones de Docencia, de revisar los programas de formación para adecuarlos a las nuevas necesidades, y de definir Áreas de Supraespecialización. Finalmente, destaca las funciones de los Colegios de Médicos como órganos desvinculados de la Administración y de las empresas.

Por lo que respecta a las preguntas concretas que se formularon, cabe destacar que un $31 \%$ de los delegados opinaron que el sistema de formación MIR, si bien era bueno, había experimentado un deterioro progresivo, y que un $41 \%$ se manifestaron a favor de su rediseño. Un $77 \%$ de los votantes opinó que debía modificarse la prueba de acceso, y un 69 $\%$ se mostró partidario de una evaluación final. Frente a un $38 \%$ de los delegados que opinaron que la formación MIR tuviera carácter autonómico, un $50 \%$ de los mismos se manifestaron a favor de un diseño estatal.

La Subponencia $3^{\text {a }}$, que recibió el apoyo de un 90 $\%$ de los delegados, hace la recomendación general de que las organizaciones profesionales y, especialmente, los Colegios de Médicos tengan un papel protagonista en la garantía de la competencia profesional. Señala la necesidad de establecer la adecuada colaboración entre las universidades, las sociedades científicas, los organismos profesionales, los responsables de la formación de postgrado y las patronales del sistema sanitario a fin de mantener la competencia , y de reclamar a la Administración la toma de medidas de incentivación de la misma. Indica la necesidad de ver la evaluación de la competencia como un instrumento de garantía más que como un elemento coercitivo, y de instaurar un sistema de recertificación profesional que evite la introducción 
de elementos de control ajenos a la profesión. Todo ello desarrollado en el marco de la Unión Europea.

En respuesta a las preguntas concretas formulados sobre la temática de esta subponencia, es de destacar que un $61 \%$ de los delegados se manifestaron partidarios de que la formación continuada fuera obligatoria tanto para los médicos del sector público como del sector privado. Hubo dispersión de opiniones respecto a las medidas que debían adoptarse con aquellos no hagan de manera regular y sistemática formación médica continuada. Un $54 \%$ de los delegados opinó que debía establecerse un sistema, no punitivo, de evaluación de la competencia profesional; sistema que para un $23 \%$ de los votantes debería tener carácter obligatorio y que, en opinión de un $47 \%$, debería corresponder a las sociedades científicas.
Cabe señalar, finalmente, que en el marco del congreso el Consejo de Colegios de Médicos de Cataluña concedió, por vez primera, los "Premios a la Excelencia Profesional", otorgados a sesenta colegiados, clasificados en seis ámbitos de actuación: "Medicina Hospitalaria", "Salud Mental, Salud Pública y Atención Sociosanitaria", "Educación Médica", "Atención Primaria", "Investigación Biomédica" y "Humanidades Médicas".

Nos resta únicamente agradecer al Consejo de Colegios de Médicos la iniciativa emprendida, de indudables consecuencias beneficiosas para el ejercicio profesional, y felicitar a los responsables de la organización del congreso por sus numerosos aciertos, y a todos los asistentes por su interés y por su eficaz participación. 